\title{
MONITORAMENTO DE MUDAS DE Allophylus edulis (A. St.-Hil., Cambess. \& A. Juss.) Radlk. PLANTADAS EXPERIMENTALMENTE NA ARBORIZAÇÃO DE RUAS DA CIDADE DE CURITIBA - PR
}

\author{
Daniela Biondi ${ }^{1}$, Luciana Leal ${ }^{2}$
}

(recebido em 01.07.2009 e aceito para publicação em 10.06.2010)

\section{RESUMO}

O monitoramento de mudas plantadas na arborização de ruas deve avaliar a adaptação das mesmas no local e os danos causados por vandalismo. Assim, esta pesquisa teve como objetivo avaliar o crescimento e os danos causados por vandalismo em mudas de Allophylus edulis plantadas experimentalmente na arborização de rua na cidade de Curitiba - PR. Em dezembro de 2006 foram plantadas 20 mudas desta espécie e estas foram monitoradas durante 24 meses, trimestralmente. No período de monitoramento as mudas apresentaram lento crescimento, com um incremento médio de $0,34 \mathrm{~cm}$ em altura total e $0,70 \mathrm{~cm}$ em diâmetro. O número de brotações podadas no segundo ano foi sete vezes menor que no primeiro ano, indicando uma característica positiva para a arborização de ruas. Mesmo que os moradores tenham sido consultados sobre o plantio, houve perda de $20 \%$ das árvores plantadas, causada por vandalismo. Também $45 \%$ delas sofreram danos no tronco, $45 \%$ tiveram o tutor tirado, $25 \%$ tiveram seu tronco quebrado e $10 \%$ tiveram entulhos em sua base do tronco. É necessário, portanto, um reforço para o aumento da sensibilização e comprometimento dos residentes com a arborização da rua.

Palavras-chave: arborização urbana, crescimento, brotações adventícias, vandalismo.

\footnotetext{
1 Engenheira Florestal, Dra., Professora Associada II, Depto. Ciências Florestais, Universidade Federal do Paraná - UFPR, Bolsista Produtividade em Pesquisa - CNPq, Curitiba - PR. E-mail: dbiondi@ufpr.br

${ }^{2}$ Engenheira Florestal, M.Sc. / Companhia Paranaense de Eletricidade - COPEL, Doutoranda em Engenharia Florestal - UFPR. E-mail: Iuciana.leal@copel.com
} 
MONITORING OF Allophylus edulis (A. St.-Hil., Cambess. \& A. Juss.) Radlk. SEEDLINGS USED IN STREET TREE-PLANTING IN CURITIBA, PARANÁ

\section{ABSTRACT}

The seedlings monitoring used in street tree-planting should evaluate the seedling adaptation to location and damage from vandalism. The objective of this study was to evaluate growth and damage caused by vandalism in Allophylus edulis seedlings planted experimentally in street trees in Curitiba - PR. Twenty Allophylus edulis seedlings were planted in December 2006 and were monitored once every trimester for 24 months. During the monitoring period, the seedlings presented slow growth with average increments of $0.34 \mathrm{~cm}$ in height and 0.70 $\mathrm{cm}$ in diameter. The number of shoots pruned in the second year was seven times smaller than in the first year, indicating a positive characteristic for street tree-planting. Although, residents had been consulted about the planting, there was a $20 \%$ tree loss due to vandalism. Additionally, $45 \%$ suffered damage to the trunk, $45 \%$ had the stake removed, $25 \%$ had the trunk broken, and $10 \%$ had debris at the trunk base. Therefore, efforts are needed to raise the residents' awareness and commitment to street tree-planting.

Keywords: urban tree-planting, native species, growth, adventitious shoots, vandalism. 


\section{INTRODUÇÃO}

A utilização de espécies nativas em áreas urbanas, além de valorizar a qualidade de vida local e contribuir para a criação de belezas cênicas singulares e atrativas, é também indicada por contribuir para a proteção e valorização da flora local. Entretanto, quando espécies nativas são utilizadas na arborização de cidades, devido às mudanças de habitat e condições adversas a que são submetidas no novo ambiente urbano, especialmente condições locais de solos e espaços de crescimento disponíveis, sofrem mudanças de ordem fisiológica e de crescimento, diferentemente das geralmente encontradas em ambiente de mata fechada nativa. Portanto, é importante considerar no planejamento da arborização urbana questões como: condições locais, espaço físico para crescimento e desenvolvimento da planta, e principalmente, as características ecológicas específicas das espécies a serem utilizadas (KULCHETSCKI et al., 2006).

No meio urbano muitas vezes, a espécie introduzida assume um comportamento que foge dos padrões esperados, observado no meio natural, como a forma da copa, o tipo de raiz e a susceptibilidade a pragas, doenças e poluição (BIONDI; ALTHAUS, 2005). Por isso, é muito importante o monitoramento das espécies após o plantio.

Biondi et al. (1990) consideram o monitoramento das mudas plantadas, a $3^{\circ}$ fase do plano de arborização de ruas, a qual poderá ser executada tanto pela empresa de obras como pela equipe que elaborou o plano. Os autores dividem o monitoramento das mudas em duas etapas: (1) avaliação da adaptação das mudas no local e (2) avaliação da ação conscientizadora. A $1^{\text {a }}$ etapa deve ser realizada depois de 30 dias do plantio para avaliação do índice de pega das mudas plantadas e investigação das possíveis causas de danos. $E$ nos primeiros seis meses serão investigadas as causas de origens abióticas e bióticas. A $2^{\mathrm{a}}$ etapa, que pode ser realizada paralela a $1^{\text {a }}$, é a avaliação do índice de vandalismo. Caso o índice de replantio por causa do vandalismo seja alto, acima de $15 \%$, é recomendado o fortalecimento das ações educativas realizadas antes do plantio.

O período de monitoramento de espécies introduzidas deve estar associado ao seu crescimento ou a velocidade de desenvolvimento. O período mais crítico é o estágio inicial da árvore devido à fase de adaptação ao meio urbano. Depois, o monitoramento pode ser estabelecido em períodos maiores. Os dados coletados devem ser sobre as características das árvores (altura, diâmetro do tronco, densidade da copa, área foliar, incidência de pragas e doenças) e sobre as características do local (graus de poluição, fluxo de veículos e pedestres, solo, umidade, vento, radiação e outros). Quando a espécie é totalmente

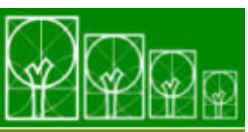

S $\cdot \mathbf{B} \cdot \mathbf{A} \cdot \mathbf{U}$ Soc. Bras. de Aborização Urbana 
desconhecida em áreas urbanas, o monitoramento deve ser contínuo com as avaliações periódicas estabelecidas de 5 em 5 anos ou de 10 em 10 anos (BIONDI; ALTHAUS, 2005).

Allophylus edulis (A. St.-Hil., Cambess. \& A. Juss.) Radlk. - Sapindaceae, conhecida vulgarmente como vacum, vacunzeiro, chal-chal, baga-de-morcego, fruta-de-pombo, murtavermelha, entre outros (REITZ, 1980; LORENZI, 1992; BACKES; IRGANG, 2004), no Brasil é encontrada no Amazonas, Ceará, Bahia, Mato Grosso, Minas Gerais, Rio de Janeiro, São Paulo, Paraná, Santa Catarina e Rio Grande do Sul. Também nas Guianas, Bolívia, Paraguai, Uruguai e Argentina (REITZ, 1980; BACKES; IRGANG, 2004). Ocorre na Floresta Ombrófila Mista Montana e Aluvial (RODERJAN et al., 2002), tanto em locais com luminosidade intensa como à sombra, predominando nos estratos médio e interior da floresta (SANCHONETE, 1989).

A espécie é facilmente reconhecida por suas folhas compostas por três folíolos serrados, com intensa floração branca e especialmente por seus frutos vermelhos que the conferem um contraste vivo sobre sua copa densa verde-escura (BACKES; IRGANG, 2004). Planta semicaducifólia, possui copa simpodial e arredondada (GIMENEZ; MOGLIA, 2003), fechada, com folhagem densa e ramificação dicotômica abundante (REITZ, 1980).

Possui porte pequeno, de até $10 \mathrm{~m}$ de altura, com fuste de até $45 \mathrm{~cm}$ de diâmetro (BACKES; IRGANG, 2004). É citada como arvoreta ou árvore de 5 - $20 \mathrm{~m}$ de altura e 15 - 30 cm de diâmetro na altura do peito por Reitz (1980) e altura de 6 a 10 m, com tronco de 20 $30 \mathrm{~cm}$ de diâmetro por Lorenzi (1992); podendo atingir $20 \mathrm{~m}$ de altura e $30 \mathrm{~cm}$ de diâmetro segundo Carvalho et al. (2004). A taxa de crescimento é média (GIMENEZ; MOGLIA, 2003).

Por ser bastante ornamental esta espécie pode ser empregada com sucesso na arborização de ruas e praças (LORENZI, 1992; CARVALHO et al., 2004), além de ser considerada como árvore ideal para plantio em pequenos espaços (BACKES; IRGANG, 2004). É uma planta rústica que vem sendo utilizada em praças, parques e jardins do município de Porto Alegre, demonstrando boa resistência às condições urbanas. A natureza do sistema radicial, a adaptabilidade tanto à luz quanto à sombra e o médio porte dessa espécie permitem que se recomende o seu plantio em calçadas e canteiros centrais de avenidas, inclusive onde há rede elétrica e/ou telefônica (SANCHONETE, 1989).

Esta pesquisa teve como objetivo avaliar o crescimento e os danos causados por vandalismo em mudas de Allophylus edulis plantadas experimentalmente na arborização de rua na cidade de Curitiba - PR.

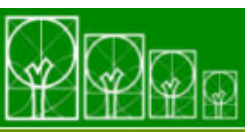

S $\cdot \mathbf{B} \cdot \mathbf{A} \cdot \mathbf{U}$ Soc. Bras. de Aborização Urbana 


\section{MATERIAL E MÉTODOS}

Em dezembro de 2006 foi realizado o plantio experimental de 20 mudas de Allophylus edulis na Rua Heitor de Andrade, bairro Jardim das Américas, cidade de Curitiba - PR, localizada a $25^{\circ} 25^{\prime}$ de latitude Sul e $49^{\circ} 16^{\prime}$ de longitude Oeste. Este experimento foi realizado em parceria entre a Universidade Federal do Paraná e a Prefeitura Municipal de Curitiba.

A rua escolhida estava localizada em área residencial e possui largura de 19,80 m (calçada e pista de rolamento), calçada com largura de 6,30 m e passeio com 0,95 m, com canteiro gramado e sem presença de redes de distribuição de energia elétrica. $\mathrm{Na}$ ocasião do plantio, os moradores foram consultados se queriam o plantio das mudas em frente a sua casa.

As mudas, com tamanho médio de $1,98 \mathrm{~m}$ de altura e $0,95 \mathrm{~cm}$ de diâmetro do colo, foram plantadas num espaçamento médio de $8 \mathrm{~m}$ e tutoradas com estacas de bambu. Para o plantio foram abertas covas de tamanho mínimo de $60 \times 60 \times 60 \mathrm{~cm}$. Foi substituído aproximadamente $2 / 3$ do solo original da cova por substrato orgânico (conhecido como terra de mata) utilizado pela prefeitura em plantios de espécies arbóreas. As mudas não foram adubadas e nem irrigadas após o plantio.

As mudas foram monitoradas durante um período de 24 meses. Trimestralmente foram mensuradas as variáveis: altura total $(\mathrm{m})$, diâmetro à altura do peito $(\mathrm{cm})$ e o número de brotações que surgiram abaixo da altura de bifurcação (incluindo gemas, ramos e galhos), as quais eram podadas nas avaliações realizadas. Em cada avaliação também foram avaliados os danos por vandalismo: mudas retiradas, mudas quebradas, mudas com danos no tronco, mudas com colo coberto por entulhos e mudas sem tutor.

Para o cálculo do incremento em altura total e diâmetro das mudas foram desconsideradas aquelas que por atos de vandalismo foram quebradas.

\section{RESULTADOS E DISCUSSÃO}

\section{Avaliação do crescimento das mudas plantadas na rua}

Durante o período de monitoramento, as mudas de Allophylus edulis apresentaram um crescimento lento, com um incremento de $0,34 \mathrm{~cm}$ de altura e $0,70 \mathrm{~cm}$ de diâmetro em

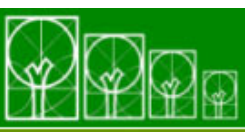

$\mathbf{S} \cdot \mathbf{B} \cdot \mathbf{A} \cdot \mathbf{U}$ Soc. Bras. de Aborização Urbana 
24 meses. Segundo Biondi e Althaus (2005), o período mais crítico no monitoramento é o estágio inicial da árvore devido à fase de adaptação ao meio urbano.

Observa-se na Figura 1 que a curva de crescimento em altura das mudas apresentase de forma ascendente, com maior pico nos meses referentes às estações primaveraverão. A Figura 2 demonstra o maior incremento médio em altura de Allophylus edulis que foi na estação da primavera do primeiro ano de plantio.

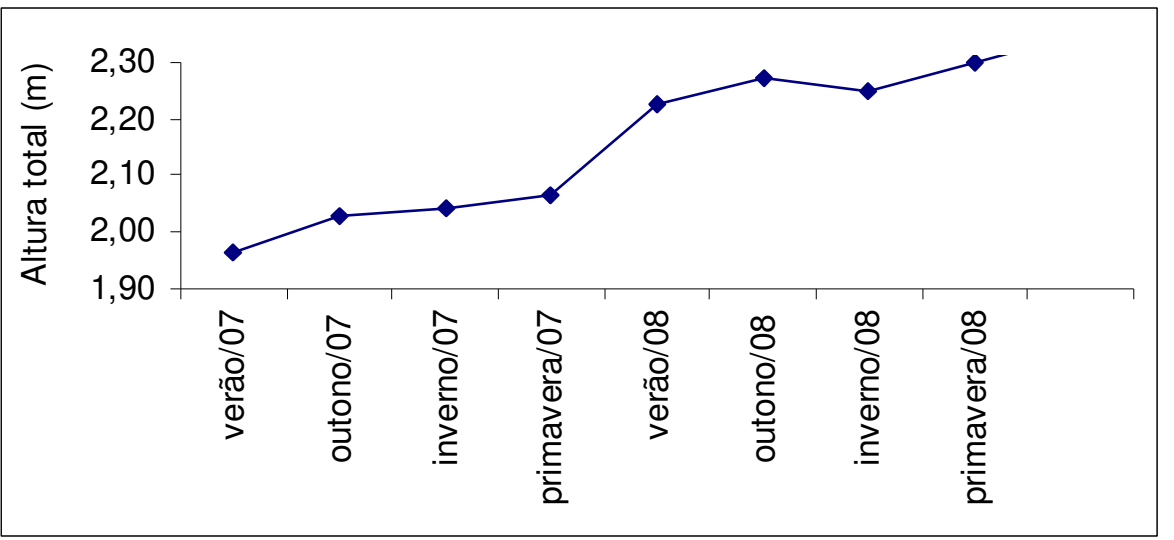

FIGURA 1 - Crescimento em altura total de mudas de Allophylus edulis

O maior crescimento em altura nestas estações do ano tanto pode ser justificado pelo padrão do período vegetativo como pelas condições meteorológicas do local no período, mostradas nas Figuras 3 e 4. Em Curitiba, geralmente a primavera-verão é caracterizada por períodos de maior precipitação. Segundo Kramer e Kozlowski (1960), o crescimento das plantas é limitado com mais frequência por deficiências hídricas do que por qualquer outro fator interno. Como não houve nenhuma medida de manutenção das mudas, como adubação, sugere-se que o abastecimento de água pela chuva pode ter sido o promotor deste acréscimo do crescimento em altura. Kramer e Kozlowski (1960), explicam que é bem conhecido que as deficiências em água, bem como outras condições desfavoráveis do meio, provocam a paralisação prematura do crescimento. Também se tem demonstrado que melhorando o meio pela irrigação, fertilização ou mediante remoção da vegetação concorrente, se aumenta a duração do período e o total do crescimento das extremidades caulinares. 


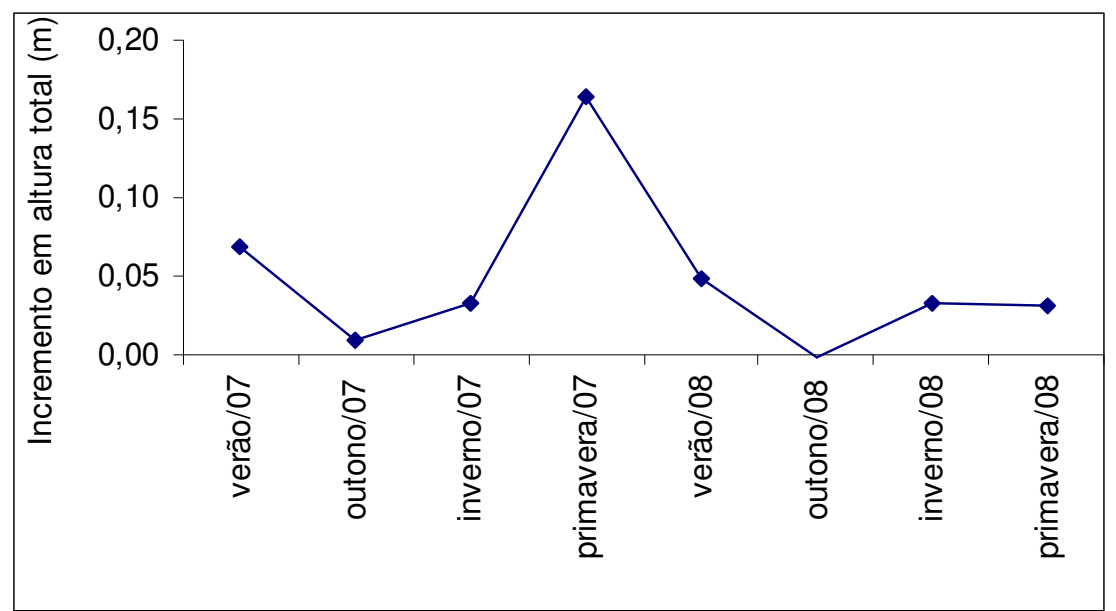

FIGURA 2 - Incremento médio em altura total de mudas de Allophylus edulis nas estações do ano

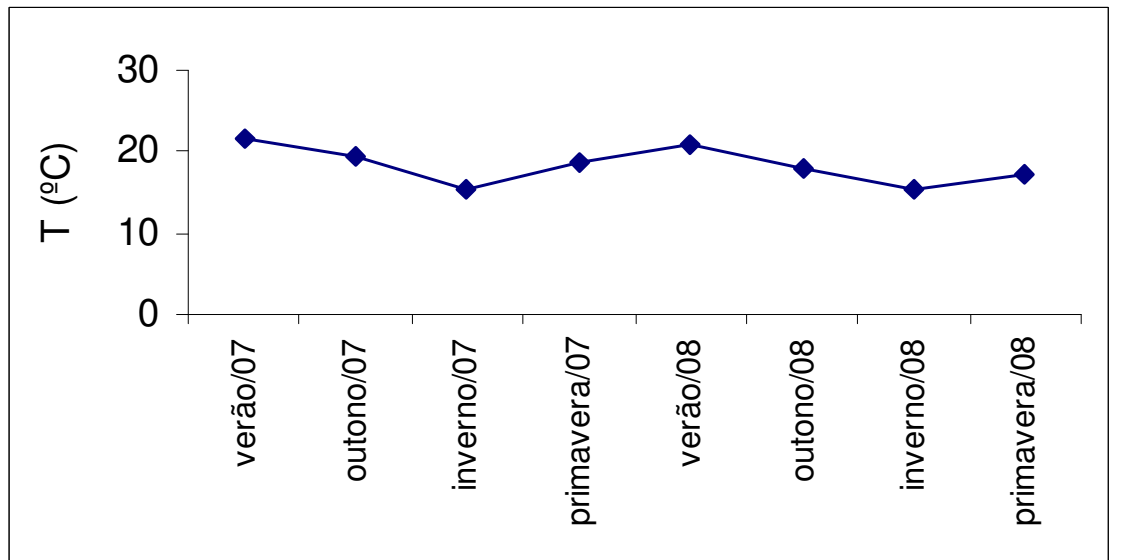

FIGURA 3 - Temperatura média no período de monitoramento das mudas de Allophylus edulis

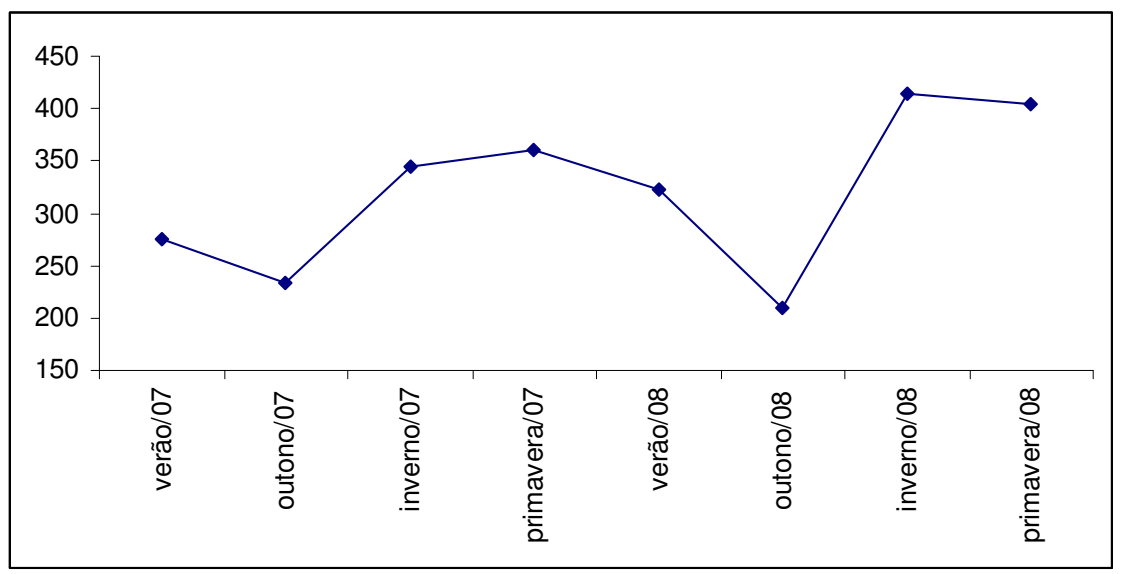

FIGURA 4 - Precipitação acumulada no período de monitoramento das mudas de Allophylus edulis 
Na Figura 5 observa-se que as mudas apresentam um crescimento em diâmetro quase constante no primeiro ano de plantio, com um grande acréscimo na primavera do segundo ano. Comparando as Figuras 2 e 5, percebe-se que na primavera há uma intercalação de crescimento - quando houve um maior incremento em altura, não houve um maior incremento em diâmetro e vice-versa. Kramer e Kozlowski (1960) explicam que na maior parte das espécies, o crescimento em diâmetro na parte inferior do tronco inicia-se mais tarde e continua mais tempo do que o crescimento em altura.

Embora, nesta pesquisa, seja mais visível a influência das condições da primavera no crescimento em altura, Kramer e Kozlowski (1960) afirmam que o crescimento em diâmetro, tal como o crescimento em altura, apresenta periodicidade tanto diária como estacional, embora o engrossamento pareça ser consideravelmente mais sensível às condições do meio do que no crescimento em altura. Complementa ainda que a periodicidade estacional do crescimento em altura é, sobretudo, regulada pelos fatores genéticos internos, enquanto o crescimento em diâmetro é sensível às condições ambientais.

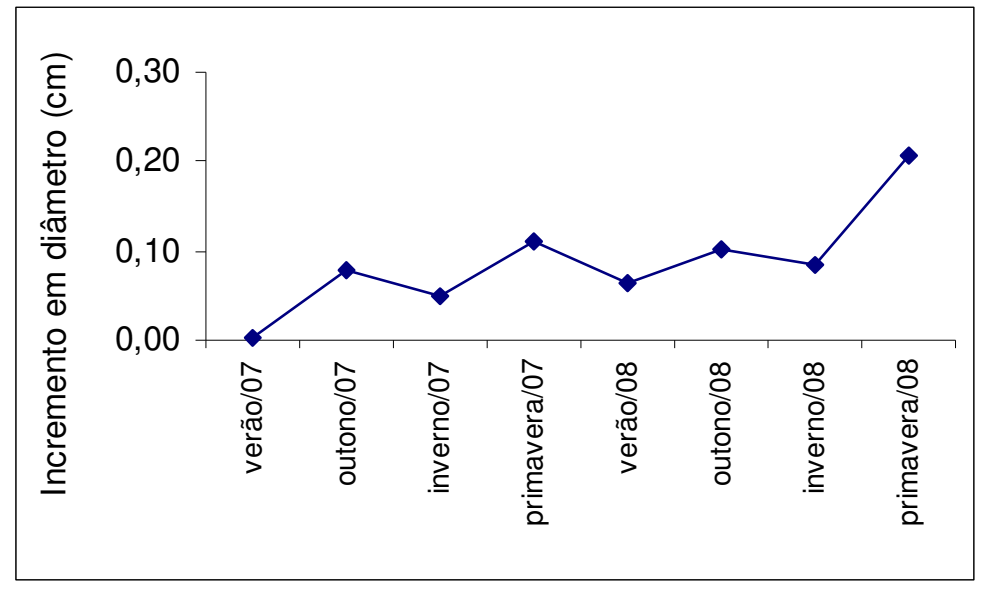

FIGURA 5 - Incremento médio em diâmetro de Allophylus edulis nas estações do ano

Biondi et al. (2007), em monitoramento com mudas de Allophylus edulis em viveiro de espera, constataram que o incremento em diâmetro nas avaliações semestrais teve o mesmo comportamento que o incremento em altura, com maior aumento no período primavera-verão.

No primeiro ano de plantio, as mudas apresentaram um maior número de brotações no tronco (Figura 6). No segundo ano houve uma grande diminuição de brotação, sendo 
sete vezes menor do que o primeiro ano. Este comportamento é muito positivo para o padrão de árvores de rua.

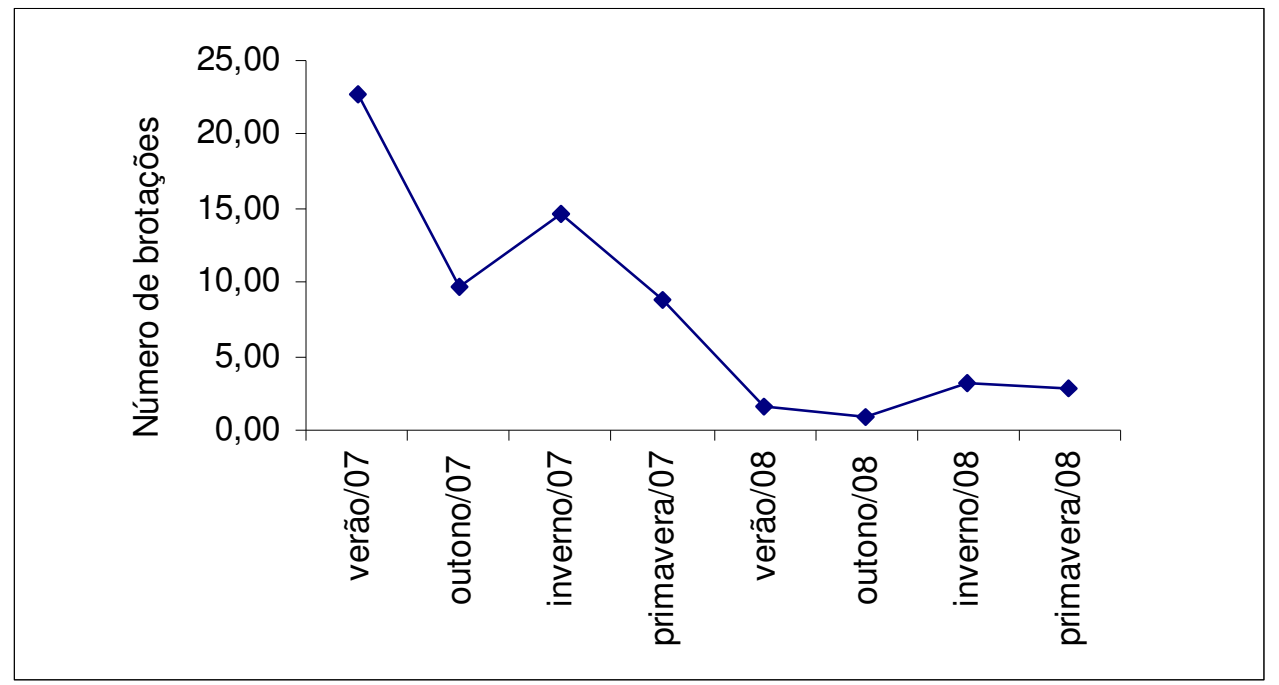

FIGURA 6 - Número de brotações no tronco Allophylus edulis nas estações do ano

Segundo Biondi e Leal (2009), para as árvores plantadas em calçadas, qualquer prédisposição da espécie em desenvolver brotação no tronco ou na raiz gera conflitos com os pedestres (pela maior ocupação da área do passeio) e, consequentemente, exige maior manutenção, aumentando assim os custos. Além disso, a eliminação frequente destas brotações pode ser uma porta de entrada a pragas e doenças pelos cortes deixados. Biondi e Althaus (2005) constataram em Lagerstroemia indica L. (extremosa), a existência de brotação adventícia muito intensa exigindo manutenção contínua tanto nas mudas em viveiro como nas árvores nas ruas de Curitiba.

A produção de ramos adventícios (Figura 7) pode também ainda estar desviando ou utilizando reservas ou energia que deviam estar sendo dirigida para outras regiões de crescimento, como a gema apical ou altura e diâmetro. Biondi et al. (2007) complementam dizendo que a remoção dos ramos, além de colaborar com o crescimento, ajuda a produzir uma muda com maior altura de bifurcação, isto é, caule livre de ramificações até o início do esgalhamento que forma a copa.

Segundo Kozlowski (1971) e Zimmermann e Brown (1974), o crescimento de brotos ou ramos reflete uma resposta integrada das condições climáticas e edáficas impostas e fatores bióticos através da influência interna dos processos fisiológicos da árvore. Os componentes ambientais que podem influenciar a produção de ramos são: luz, água 
temperatura, suprimento mineral, composição atmosférica, propriedade física e química do solo, insetos, outras plantas e vários animais. Pode ainda ser grandemente influenciado pelas práticas culturais e crescimento reprodutivo, como também aos fatores genéticos e envelhecimento das árvores.
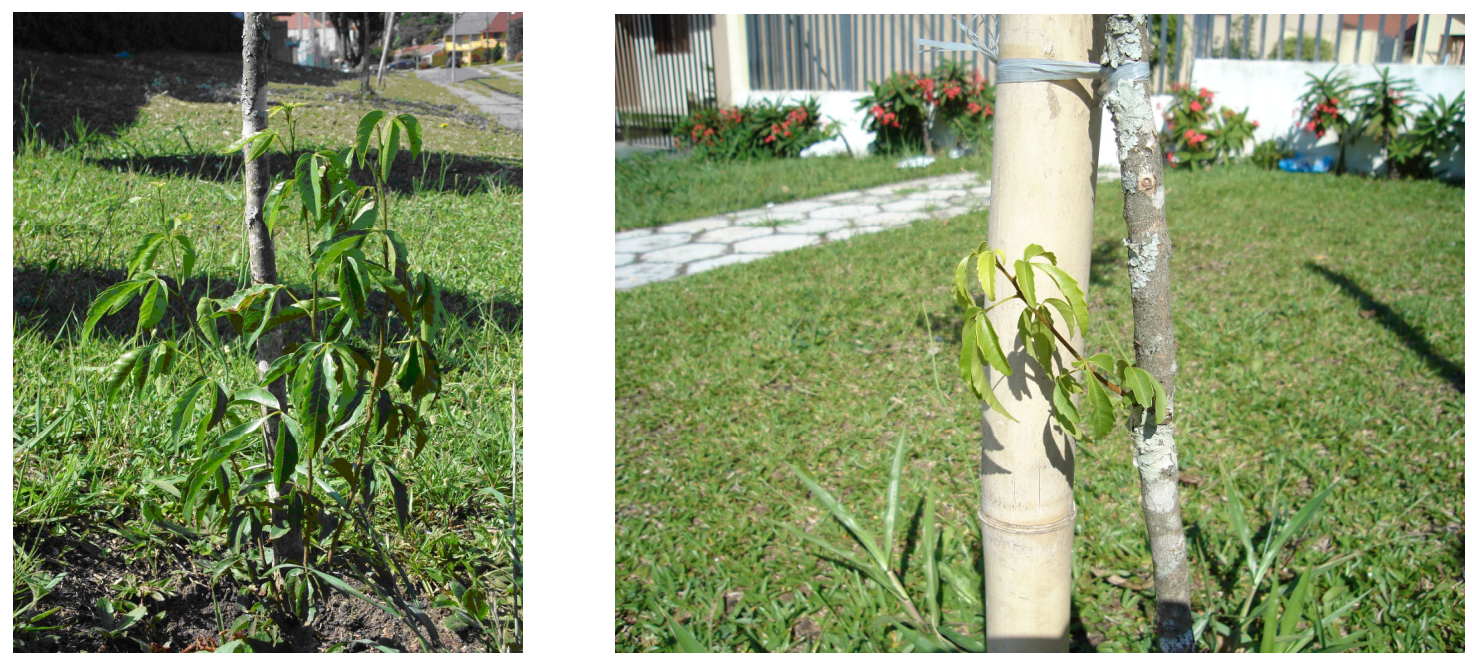

FIGURA 7 - Brotações adventícias no tronco de mudas de Allophylus edulis

Diante do exposto, fica muito difícil apontar um único fator responsável pela alta produção de ramos no tronco das mudas no primeiro ano de plantio, já que as mesmas estão pré-dispostas a uma série de componentes ambientais associado à manutenção do tronco (retirada dos ramos a cada três meses). Como o comportamento dos ramos das mudas plantadas nas calçadas foi analisado em função das estações do ano (Figura 6), pode-se inferir apenas a respeito das condições climáticas e práticas culturais (poda).

A grande produção de ramos durante a estação primavera-verão é justificável pela ocorrência do período vegetativo e as condições favoráveis do clima desta estação em Curitiba (alta intensidade de luz, temperatura e maior ocorrência de chuva). Mas, observa-se na Figura 6 que ocorreu um fato curioso, no inverno houve um sensível aumento na produção de ramos, mesmo com a realização da poda anteriormente e dormência vegetativa. Kozlowski (1971) diz que quando as árvores apresentam resistência ao frio, geralmente elas têm uma marcada periodicidade na produção de ramos durante todo ano. Sendo assim, o rigor do clima não faz a planta entrar em completa dormência vegetativa.

\section{Avaliação dos danos às mudas plantadas na rua}

Embora os residentes da rua tenham sido consultados, antes do plantio, houve uma perda de $20 \%$ das mudas por vandalismo e $25 \%$ das mudas ficaram comprometidas (mudas

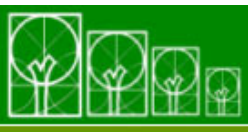

$\mathbf{S} \cdot \mathbf{B} \cdot \mathbf{A} \cdot \mathbf{U}$ Soc. Bras. de Aborização Urbana 
quebradas). Não se tem certeza se estes danos foram causados pelos residentes ou transeuntes.

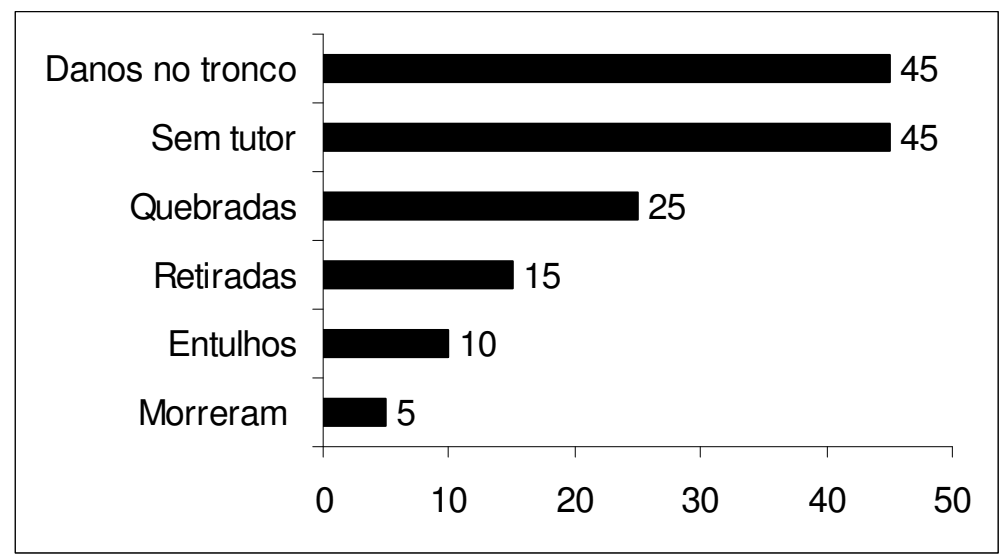

FIGURA 8 - Percentagem de danos às mudas de Allophylus edulis por vandalismo

Dos $20 \%$ das mudas vandalizadas (Figura 8 ), $45 \%$ sofreram danos no tronco, $45 \%$ tiveram o tutor tirado, $25 \%$ tiveram seu tronco quebrado, $15 \%$ foram arrancadas, $10 \%$ tiveram entulhos em sua base do tronco (Figura 9) e 5\% morreram.
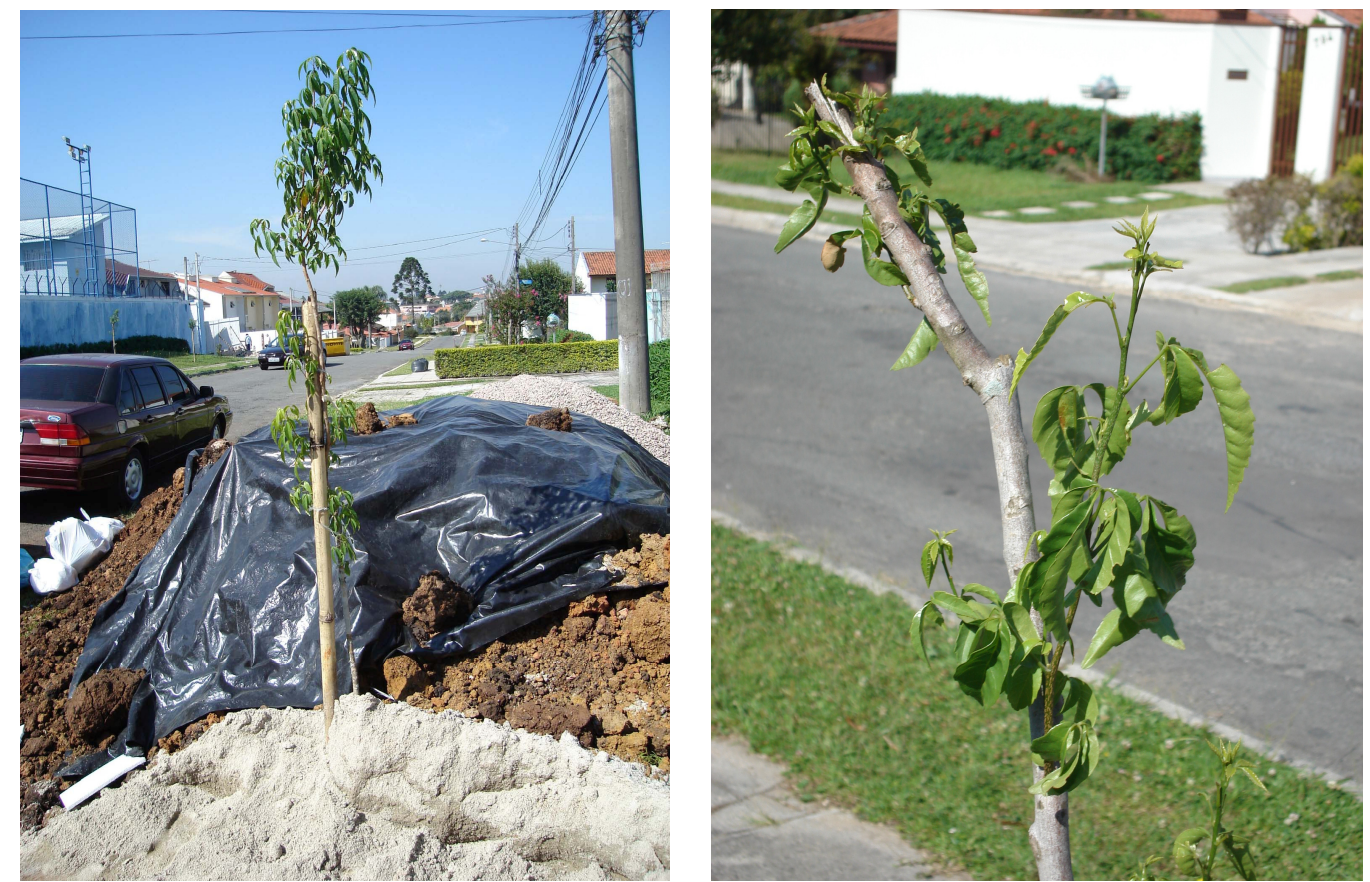

FIGURA 9 - Vandalismos em mudas de Allophylus edulis - soterramento da muda por entulho e quebra da gema apical

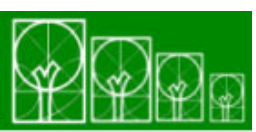


Em Curitiba, a Prefeitura Municipal calcula que, de aproximadamente 10 mil novas árvores plantadas por ano nas vias públicas, 3,5 mil são destruídas por vandalismo. Para proteger as árvores das ruas de Curitiba de ações de vândalos, o Horto Municipal, onde as mudas são produzidas, está mudando o padrão de produção das plantas. A partir de 2010, as novas árvores serão plantadas em seus locais definitivos apenas quando tiverem altura mínima de 2,5 m e tronco de $10 \mathrm{~cm}$ de diâmetro (GAZETA DO POVO, 2009).

O vandalismo não é um problema restrito a arborização de ruas de Curitiba. De acordo com Biondi (2000), está presente em quase todas as cidades do mundo, embora varie em proporções. Em Hong Kong, danos com vandalismo atingem aproximadamente 10 a 15\% das árvores plantadas (JIM, 1987). Já em algumas cidades européias afeta $30 \%$ dos plantios, segundo levantamento realizado entre 1999 e 2001 (PAULEIT et al., 2002). No Reino Unido, acima de $30 \%$ dos novos plantios de árvores de rua foram vandalizados, e o nível de vandalismo foi inversamente relacionado à qualidade das árvores plantadas. Os maiores causadores de danos às árvores urbanas foram às escavações para encanamentos de esgoto, água ou eletricidade e os trabalhos de construção (NILSSON et al., 2005).

No Brasil, Teixeira et al. (2009) avaliando 2788 indivíduos arbóreos, pertencentes a arborização de um conjunto habitacional em Santa Maria - RS, verificaram 12,5\% de danos nas árvores por vandalismo. Sirvinskas (2009) constatando a alta percentagem de danos às árvores da cidade de São Paulo por vandalismo (27,35\%), diz que existem várias razões para o triste e alarmante vandalismo que tem se alastrado na cidade, mas a principal é a falta de educação ambiental e a despreocupação com o futuro, aliado ao fato da certeza da impunidade.

A falta de comprometimento e conscientização da população em relação à importância da arborização urbana na cidade pode ser o maior fator responsável da ocorrência do vandalismo. Coltro e Miranda (2007) avaliando na cidade de Irati - PR, o nível de satisfação da população em relação a arborização urbana, constataram que $67,16 \%$ da população percebem e não se agradam do vandalismo que ocorrem nas árvores. Em Piaçú - MG, um dos principais fatores responsáveis pela situação precária da arborização urbana é a falta de uma política de educação ambiental que resulte em uma maior conscientização e esclarecimento da população para o plantio, proteção e conservação da arborização (MORAIS et al., 2008). Em Marechal Cândido Rondon - PR, numa pesquisa sobre a avaliação da arborização urbana pelos residentes, $73 \%$ dos entrevistados declararam que colaboram de alguma maneira com a arborização municipal de várias maneiras: plantando árvores, não danificando e não maltratando (MALAVASI; MALAVASI, 2001).

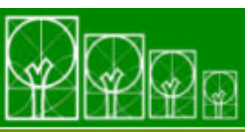

$\mathbf{S} \cdot \mathbf{B} \cdot \mathbf{A} \cdot \mathbf{U}$ Soc. Bras. de Aborização Urbana 
O vandalismo tanto prejudica o crescimento das árvores através dos danos causados como gera um grande prejuízo ao município através das várias reposições. Segundo Jim (2004), o vandalismo causa danos diretos e indiretos nas árvores, como injúrias nos galhos e troncos e quebra de galhos. Segundo Milano (1994), os custos da arborização são encarecidos pelas ações da população sobre as árvores, notadamente pelo vandalismo.

O custo de produção de uma muda de lento crescimento, que permanece cerca de cinco anos em viveiro de espera, como é o caso de Allophylus edulis (BIONDI et al., 2007), conforme dados apresentados por Leal (2007), é de $R \$ 88,43$ e o custo da operação de plantio de uma muda é de $R \$ 43,23$, totalizando $R \$ 131,66$. Assim, o custo de plantio das 20 mudas utilizadas neste experimento totalizaria $R \$ 2.633,20$ e as perdas por vandalismo ( $20 \%$ das mudas) poderiam ser quantificadas em $R \$ 526,64$.

\section{CONCLUSÕES}

O crescimento das mudas de Allophylus edulis após dois anos de plantio é lento, podendo ser uma resposta das condições ambientais (climáticas e/ou edáficas) do meio urbano e as práticas silviculturais (poda) realizadas durante o monitoramento.

Pelo alto índice de vandalismo às mudas, é necessário, um reforço para o aumento da sensibilização dos transeuntes e comprometimento dos residentes com a arborização da rua.

\section{REFERÊNCIAS}

BACKES, P.; IRGANG, B. Mata Atlântica. As árvores e a paisagem. Porto Alegre: Paisagem do Sul, 2004. p. 351.

BIONDI, D. Curso de arborização urbana. Curitiba: [s.n.], 2000. 45 p.

BIONDI, D.; ALTHAUS. M. Árvores de Rua de Curitiba: cultivo e manejo. Curitiba: FUPEF, 2005. 
BIONDI, D.; BATISTA, A. C.; FERREIRA, R. L. C. Plano de Arborização para o bairro de Brasília Teimosa - Recife, PE. In: CONGRESSO NACIONAL SOBRE ARBORIZAÇÃO URBANA, III, 1990, Curitiba-PR. Anais... Curitiba: FUPEF, p.211-219, 1990.

BIONDI, D.; LEAL, L. Comportamento silvicultural de espécies nativas em viveiro de espera para uso potencial em arborização de ruas. Scientia Forestalis, Piracicaba, v.37, n.83, set.2009 (no prelo).

BIONDI, D.; LEAL, L.; COBALCHINI, J. L. Tratamentos silviculturais em mudas de Allophylus edulis (A. St.-Hil., Cambess. \& A. Juss.) Radlk. para arborização de ruas. Floresta, Curitiba, v.37, n.3, p.437-444, 2007.

CARVALHO, J.; SOUZA, S. G. A.; RODERJAN, C. V.; MARQUES, M. C. M. Estrutura de uma população de Allophylus edulis (St. Hill.) Radlk. em floresta ciliar do rio Barigui, Araucária

PR.

Disponível

em:

http://www.adaltech.com.br/evento/museugoeldi/resumoshtm/resumos/R0451-1.htm> Acesso em: 12 agosto 2004.

COLTRO, E. M.; MIRANDA, G. M. Levantamento da arborização urbana pública de Irati - PR e sua influência na qualidade de vida de seus habitantes. Revista Eletrônica Lato Sensu, Irati, v.2, n.1, p.1-22, 2007.

GAZETA

DO

POVO.

Disponível

em:

<http://portal.rpc.com.br/gazetadopovo/vidaecidadania/conteudo.phtml?tl=1\&id=914415\&tit= Para-evitar-vandalismo-arvores-serao-cultivadas-por-5-anos-antes-de-ir-para-as-ruas $>$. Acesso em: 18 agosto 2009.

GIMENEZ, A. M.; MOGLIA, J. G. Árboles del Chaco Argentino: Guía para el reconocimiento dendrológico. Santiago del Estero: El Liberal S. R. L., 2003. p. 215.

JIM, C. Y. Evaluation of heritage trees for conservation and management in Guangzhou City (China). Environmental Management, New York, v. 33, n. 1, p. 74-86, 2004. 
JIM, C. Y. The status and prospects of urban trees in Hong Kong. Landscape and Urban Planning, Amsterdam, v.14, p.1-20, 1987.

KOZLOWSKI, T. Growth and development of trees. London: Academic Press. Inc., 1971. $443 \mathrm{p}$.

KRAMER, P. J.; KOZLOWSKI, T. Fisiologia das árvores. Lisboa: Fundação Calouste Gulbenkian, 1960. 745 p.

KULCHETSCKI, L.; CARVALHO, P. E.; KULCHETSCKI, S. S.; RIBAS, L. L. F.; GARDINGO, J. R. Arborização urbana com essências nativas: uma proposta para a região centro-sul brasileira. Publ. UEPG Ci. Exatas Terra, Ci. Agr. Eng., Ponta Grossa, v.12, n.3, p.25-32, 2006.

LEAL, L. Custos das árvores de rua - Estudo de caso: cidade de Curitiba / PR. Curitiba, 2007. 115f. Dissertação (Mestrado em Engenharia Florestal) - Setor de Ciências Agrárias, Universidade Federal do Paraná.

LORENZI, H. Árvores brasileiras: manual de identificação e cultivo de plantas arbóreas nativas do Brasil. Nova Odessa: Plantarum, 1992. p. 315.

MALAVASI, U. C.; MALAVASI, M. M. Avaliação da arborização urbana pelos residentes estudo de caso em Mal. Cândido Rondon, Paraná. Revista Ciência Florestal, Santa Maria, v.11, n.1, p.189-193, 2001.

MILANO, M. S. Arborização urbana. In: UNILIVRE - Universidade Livre do Meio Ambiente. Curso sobre arborização urbana. Curitiba: UNILIVRE/PMC, 1994. p.01-52.

MORAIS, F. G.; REZENDE, A. R.; OSEAS, K. M.; OliveIRA, M. A.; ARAUJO, A. A. C. Levantamento e avaliação da arborização da zona urbana da cidade de Ipiaçú-MG. Disponível em:

http://www.ituiutaba.uemg.br/biologia/admin/projetos/projetos/b0a4d6d6cb.pdf>. Acesso em: 03 julho 2009. 
NILSSON, K.; KONIJNENDIJK, C.; RANDRUP, T. B. Research on urban forests and trees in Europe. In: KONIJNENDIJK, C. C.; NILSSON, K.; THOMAS B. RANDRUP, T. B.; SCHIPPERIJN, J. (Eds.). Urban forests and trees: a reference book. Springer-Verlag: Berlin, 2005. p. 445-463.

PAULEIT, S.; JONES, N.; GARCIA-MARTINS, G.; GARCIA-VALDECANTOS, J. L.; RIVIERI, L. M.;VIDAL-BEAUDET, L.; BODSON, M.; RANDRUP, T. B. Tree stablishment practice in towns and cities: results from a European survey. Urban Forestry and Urban Greening, California, v.1, n.2, p.83-96, 2002.

REITZ, P. Sapindáceas. In: REITZ, P. Flora Ilustrada Catarinense. Itajaí-SC: Herbário Barbosa Rodrigues, 1980. p.108-112.

RODERJAN, C. V., GALVÃO, F., KUNIYOSHI, Y. S., HATSCHBACH, G. G. As unidades fitogeográficas do Estado do Paraná. Ciência \& Ambiente, Santa Maria, n. 24, p. 78 - 118, 2002.

SANCHONETE, M. C. C. Frutíferas nativas úteis à fauna na arborização urbana. Porto Alegre: SAGRA, 1989. 306 p.

SIRVINKAS, L. P. Arborização urbana e meio ambiente - Aspectos jurídicos. Disponível em:

http://www.mp.ba.gov.br/atuacao/ceama/material/doutrinas/arborizacao/arborizacao_urbana _meio_ambiente_aspectos_juridicos.pdf>. Acesso em: 03 julho 2009.

TEIXEIRA, I. F.; SANTOS, N. R. Z.; BALEST, S. S. Percepção ambiental dos moradores de três loteamentos particulares em Santa Maria (RS) quanto a arborização de vias públicas. Rev. SBAU, Piracicaba, v.4, n.1, p.58-78, 2009.

ZIMMERMANN, M. H.; BROWN, C. L. Trees structure and function. New York: SpringerVerlag New York Inc. 1974. 336p. 